BMJ Open

Diabetes

Research

\& Care

\title{
Mediterranean style diet is associated with low risk of new-onset diabetes after renal transplantation
}

\author{
Maryse C J Osté, ${ }^{1}$ Eva Corpeleijn, ${ }^{2}$ Gerjan J Navis, ${ }^{1}$ Charlotte A Keyzer, ${ }^{1}$ \\ Sabita S Soedamah-Muthu, ${ }^{3}$ Else van den Berg, ${ }^{1}$ Douwe Postmus, ${ }^{2}$ \\ Martin $\mathrm{H}$ de Borst, ${ }^{1}$ Daan Kromhout, ${ }^{2,3}$ Stephan J L Bakker ${ }^{1}$
}

To cite: Osté MCJ, Corpeleijn E, Navis GJ, et al. Mediterranean style diet is associated with low risk of new-onset diabetes after renal transplantation. BMJ Open Diabetes Research and Care 2017;5:e000283. doi:10.1136/bmjdrc-2016000283

- Additional material is available. To view please visit the journal (http://dx.doi.org/ 10.1136/bmjdrc-2016000283).

Received 6 June 2016 Revised 18 October 2016 Accepted 29 October 2016

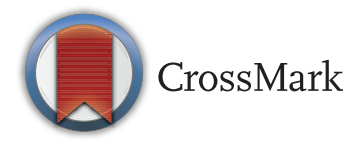

For numbered affiliations see end of article.

Correspondence to Maryse C J Osté; m.c.j.oste@umcg.nl

\section{ABSTRACT}

Objective: The incidence of new-onset diabetes after transplantation (NODAT) and premature mortality is high in renal transplant recipients (RTR). We hypothesized that a Mediterranean Style diet protects against NODAT and premature mortality in RTR.

Research design and methods: A prospective cohort study of adult RTR with a functioning graft for $>1$ year. Dietary intake was assessed with a 177item validated food frequency questionnaire. Patients were divided based on a 9-point Mediterranean Style Diet Score (MDS): low MDS (0-4 points) versus high MDS (5-9 points). A total of 468 RTR were eligible for analyses. Logistic multivariable regression analyses were used to study the association of MDS with NODAT and Cox multivariable regression models for the association with all-cause mortality.

Results: Mean \pm SD age was $51.3 \pm 13.2$ years and $56.6 \%$ were men. About $50 \%$ of the patients had a high MDS. During median follow-up of 4.0 (IQR, 0.4-5.4) years, 22 (5\%) RTR developed NODAT and $50(11 \%)$ died. High MDS was significantly associated with both a lower risk of NODAT (HR=0.23; $95 \% \mathrm{Cl} 0.09$ to $0.64 ; \mathrm{p}=0.004)$ and allcause mortality (HR=0.51;95\% $\mathrm{Cl} 0.29$ to 0.89 , $p=0.02)$ compared to low MDS, independent of age and sex. Adjustment for other potential confounders, including total energy intake, physical activity and smoking status, did not materially change the results of the analyses.

Conclusions: Dietary habits leading to high MDS were associated with lower risk of NODAT. These results suggest that healthy dietary habits are of paramount importance for RTR.

\section{INTRODUCTION}

The prevalence of patients with end-stage renal disease for which patients require chronic dialysis or renal transplantation, also called renal replacement therapy, is increasing at a rate of $7 \%$ per year. ${ }^{1}$ Renal transplantation improves quality of life and increases survival, compared to dialysis

\section{Key messages}

- Renal transplant recipients are at high risk for development of new-onset diabetes after transplantation and premature mortality.

- Dietary habits consistent with a Mediterranean style diet are associated with lower risk of development of new-onset diabetes after transplantation and premature mortality in renal transplant recipients.

- These lower risks were independent of potential confounders, including age, sex, physical activity and smoking behavior.

treatment. $^{2}{ }^{3}$ However, the results are not impressive, since a lot of factors impair survival after renal transplantation. One of these factors is new-onset diabetes after transplantation (NODAT), which is caused by the combination of insulin resistance and deficient insulin production. ${ }^{4}$ The incidence of NODAT is high and affects $\sim 20 \%$ of renal transplant recipients (RTR). ${ }^{5}$ However, a systemic review of Montori et al $t^{6}$ concluded that the incidence of NODAT varied widely from $2 \%$ to $50 \%$ in the first post-transplant year, due to inconsistencies regarding the definition of NODAT. NODAT is an important risk factor for premature mortality in RTR. ${ }^{78}$ This can partly be explained by the fact that NODAT contributes to a high cardiovascular risk, infectious complications and impaired graft survival in RTR. ${ }^{9-11}$

Patients with end-stage renal disease are often advised to consume a low protein, low potassium, low sodium diet, which is also often restricted in fluid intake, causing a diet high in energy-rich drinks, carbohydrates and fats to get enough energy. ${ }^{12}$ This diet prevents excessive generation of urea and the occurrence of hyperphosphatemia, hyperkalemia and hypertension. However, a low-protein diet gives little satiety, ${ }^{13}$ and adherence to this dietary pattern may induce problems once combined with the 
stimulation of appetite. This may be a consequence of improved renal function after renal transplantation and as a side effect of the corticosteroid treatment that is part of the immunosuppressive regimen after renal transplantation. ${ }^{14}$ Furthermore, RTR have low levels of physical activity and gain fat mass after transplantation, resulting in obesity in $26 \%$ of the participants, ${ }^{12}$ an independent risk factor for the development of NODAT. ${ }^{9}$ To reduce the incidence of NODAT and improve overall transplant success, more attention should be paid to lifestyle modification.

Meta-analyses showed that adherence to the Mediterranean diet was associated with a lower risk of diabetes. ${ }^{15}{ }^{16}$ Furthermore, Estruch et al $^{17}$ showed in the PREDIMED trial that two components of the Mediterranean diet (additional amount of extra virgin olive oil and nuts) reduced the incidence of cardiovascular events among high-risk patients. In the present study, we aimed to investigate the association of Mediterranean Style diet with the incidence of NODAT and all-cause mortality in RTR that has not yet been examined. We hypothesized that a Mediterranean Style diet is associated with a lower risk of NODAT and all-cause mortality in RTR.

\section{RESEARCH DESIGN AND METHODS}

\section{Study design and population}

The study design of this research project is a large single-center prospective cohort of RTR. All adult RTR ( $\geq 18$ years) with a functioning graft for at least 1 year who visited the outpatient clinic in the University Medical Center Groningen between November 2008 and May 2011 were invited to participate. Patients were only included if this visit was at least 1 year after transplantation. All patients had sufficient knowledge of the Dutch language and according to their patient files and no history of drug or alcohol addiction. In total 707 (86.5\%) of the initially 817 invited RTR signed a written informed consent. RTR with missing dietary data $(\mathrm{n}=81)$, diabetes mellitus $(\mathrm{DM})$ at baseline $(\mathrm{n}=152)$ or who underwent combined pancreas-kidney transplantation $(n=6)$ were excluded, leaving 468 RTR eligible for analyses. This research project was approved by the institutional review board (METc 2008/186), which adhered to the Declaration of Helsinki.

\section{Data collection and clinical end points}

Baseline data were collected during a morning visit to the outpatient clinic as described previously. ${ }^{18} 19$ Body weight and height were measured while participants wore indoor clothing without shoes. Waist and hip circumference were measured. Both systolic blood pressure and diastolic blood pressure and also heart rate were measured using a semiautomatic device (Dinamap1846; Critikon, Tampa, Florida, USA). They were measured every minute for $15 \mathrm{~min}$ in a half-sitting position to prevent white coat hypertension. Information about daily physical activity was derived using the Short QUestionnaire to ASsess Health-enhancing physical activity (SQUASH) score in time multiplied by intensity. ${ }^{20}$ Information about smoking behavior was obtained by using a questionnaire. Medication use was acquired from patient records. Furthermore, fasting blood samples were collected and patients were also asked to complete 24 hour urine collection. All RTR were informed to discard their morning urine specimen and then collect their urine for the next 24 hours, including the next morning's first specimen of the day of their visit. Creatinine clearance was based on 24 hour urinary creatinine and serum creatinine. Estimated glomerular filtration rate was calculated using the serum creatininebased Chronic Kidney Disease Epidemiology Collaboration equation. ${ }^{21}$

A semiquantitative food frequency questionnaire (FFQ) was used to collect information on dietary intake at baseline during the past month. The FFQ was developed at Wageningen University ${ }^{22}$ and consisted of 177 items. Patients filled out the self-administered FFQ at home. Frequency was recorded in times per day, week or month for each item. Expression of number of servings was in either natural units such as a slice of bread or an apple, or in household measures, for example, a cup or a teaspoon. Subsequently, all dietary data were converted into total energy and nutrient intake per day using the Dutch Food Composition Table (NEVO 2006). The FFQ was validated by comparing the protein intake of the FFQ with the protein intake calculated by the Maroni Equation, using urinary urea excretion values. ${ }^{19}$ Protein intake was similar to the estimates derived from the $\mathrm{FFQ}^{23}$

The degree to which the consumed diet resembled the traditional Mediterranean diet was calculated according to a nine-point Mediterranean Diet Score (MDS) of Trichopoulou et al. ${ }^{24}$ The MDS includes nine food groups: ratio of monounsaturated:saturated fatty acids, intake of legumes, cereals, vegetables, fruit, fish, dairy products, meat products and alcohol. ${ }^{9}{ }^{14}$ Food items of the FFQ were divided over these nine food groups (see online supplementary table S1). For each food group, the sex-specific median in grams per day was used as cut-off point for making this division, except for fish and alcohol. Patients received a score of 1 for each of the putative protective components (ratio of monounsaturated:saturated fatty acids, legumes, cereals, vegetables, fruit) if their intake was above the median. The traditional Mediterranean diet was low in dairy and meat products. Therefore, an intake below the median for these food groups was scored 1 and for an intake above the median 1. For the fish component participants received a score of 1 if they consumed more than $5 \mathrm{~g} /$ day and a score of 0 if they consumed $<5 \mathrm{~g} /$ day (<once a month). Alcohol users received a score of 1 and non-users received a score of 0 . Moderate alcohol intake is associated with low prevalence of NODAT and lower risk for mortality in RTR, when compared to 
abstainers. ${ }^{25}$ The MDS varies between 0 (lowest adherence) and 9 (highest adherence). Subsequently, all patients were divided into two groups based on the frequency distribution of the MDS: group 1 (MDS 0-4) and group 2 (MDS 5-9). We dichotomized data because of the small number of events.

In this study primary outcome measurements are the incidence of NODAT and all-cause mortality. Care-based data about the incidence of NODAT and mortality after baseline were retrieved from patient files of all RTR until 1 April 2014. NODAT was defined as a fasting plasma glucose level $\geq 7.0 \mathrm{mmol} / \mathrm{L}$ and/or use of oral hypoglycemic agents or insulin therapy for $\geq 30$ consecutive days. ${ }^{26}$ Patients developed NODAT when they had one or more of the following conditions; the patient was diagnosed with DM, used antidiabetics (oral hypoglycemic agents or insulin therapy) and/or had a fasting plasma glucose level $\geq 7.0 \mathrm{mmol} / \mathrm{L}$ or non-fasting glucose level $\geq 11.1 \mathrm{mmol} / \mathrm{L}$. The diagnosis of NODAT was made in outpatient and clinical routine. Patients were tested repeatedly before the diagnosis of NODAT was made and treatment was started. No participants were lost to follow-up.

Data on use of diuretics and/or $\beta$ blockers, use of ACE-inhibitors or angiotensin II receptor blocker, use of statins, prevalence of polycystic kidney disease and nephrosclerosis, previous viral infections (hepatitis $\mathrm{C}$ and cytomegalovirus), cumulative dose of steroids before inclusion, but during follow-up, incidence of acute rejection episodes during follow-up and used of mTOR inhibitors at baseline and during follow-up were retrieved from individual patient files. Cumulative dose of prednisolone was calculated as the sum of maintenance dose of prednisolone until inclusion and the dose of prednisolone or methylprednisolone required for treatment of acute rejection (a conversion factor of 1.25 was used to convert methylprednisolone dose to dose of prednisolone).

\section{Statistical analyses}

Variable distribution was tested with histograms and probability (Q-Q) plots. For descriptive statistics, data are presented as mean and SD when normally distributed, median and IQR when skewed distributed and number and percentage in case of categorical data. Differences between the two MDS groups to test for potential confounders were tested by an unpaired t-test for continuous variables with a normal distribution, Mann-Whitney $U$ test for continuous variables with a skewed distribution and by means of a $\chi^{2}$ test for categorical variables. All statistical analyses were performed using IBM Statistics SPSS V.22.0. For all statistical tests a statistical significance level of $\mathrm{p} \leq 0.05$ (two-tailed) was used. GraphPad Prism 5 was used to generate the figures.

Primary analyses concerned Kaplan-Meier curves of the incidence of NODAT and all-cause mortality. For NODAT multivariable logistic regression models were used because the exact dates when patients developed an event were not exactly known. For multivariable Cox regression models patients were censored at the date of last follow-up or death. Owing to the small number of NODAT and all-cause mortality the models were first adjusted for age and sex and additionally for more than two potential confounders. ${ }^{27}$ Models were checked for fulfillment of the assumptions for logistic regression and Cox regression, including the proportional hazards assumption. The assumptions were met.

\section{RESULTS}

In total 468 RTR (56.6\% men) were included with a mean \pm SD age of $51.3 \pm 13.2$ years. The frequency distribution of the MDS in these 468 RTR is presented in figure 1 . The MDS varied between 0 (lowest adherence) and 9 (highest adherence), with a mean score of $4.8 \pm 1.7$ and $54 \%$ of the patients had a high score $(>4)$. Baseline characteristics of the overall RTR population and according to high versus low MDS are shown in table 1. Age and physical activity differed significantly between the groups. Patients with a high MDS were older, had a higher physical activity score, lower fasting triglycerides and higher high-density lipoprotein (HDL)-cholesterol concentrations compared to patients with a low MDS. The percentage of smokers and total energy intake did not differ. A borderline statistical significance was found for pre-emptive transplantation, cold ischemia time and use of tacrolimus.

Median time between baseline and transplantation was 5.6 (IQR, 2.1-12.3) years. During a median follow-up of 4.0 (IQR, 0.4-5.4) years from baseline, 22 (5\%) patients developed NODAT (17 RTR in low MDS group, 5 RTR in high MDS group) and 50 (11\%) patients died (29 RTR in low MDS group, 21 RTR in high MDS group). In the low MDS group, 15 (88\%) of

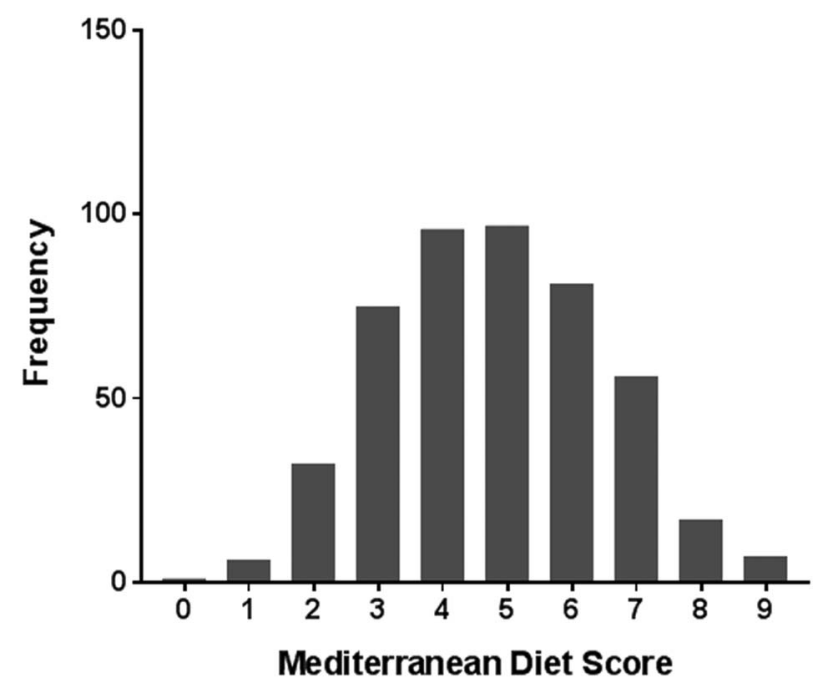

Figure 1 Frequency distribution of the Mediterranean Diet Score (MDS) in the overall RTR population (468 participants). RTR, renal transplant recipients. 
Table 1 Baseline characteristics of the overall RTR population and according to groups based on the MDS

\begin{tabular}{|c|c|c|c|c|}
\hline & $\begin{array}{l}\text { Overall RTR } \\
(n=468)\end{array}$ & $\begin{array}{l}\text { Group } 1 \text { MDS 0-4 } \\
(n=217)\end{array}$ & $\begin{array}{l}\text { Group } 2 \text { MDS 5-9 } \\
(n=251)\end{array}$ & p Value \\
\hline \multicolumn{5}{|l|}{ Demographics } \\
\hline Age, years & $51.3 \pm 13.2$ & $49.9 \pm 13.9$ & $52.5 \pm 12.4$ & 0.03 \\
\hline Male gender, n (\%) & $265(56.6)$ & $124(57.1)$ & $141(56.2)$ & 0.83 \\
\hline Smoking behavior (current smoker), $\mathrm{n}(\%)$ & $60(12.8)$ & $29(13.4)$ & $31(12.4)$ & 0.64 \\
\hline Total energy intake, kcal/day & $2199 \pm 656$ & $2168 \pm 696$ & $2225 \pm 619$ & 0.35 \\
\hline Physical activity score (timexintensity) & 5605 (2885-8647) & 5060 (2070-8385) & $6000(3480-8700)$ & 0.03 \\
\hline Weight, kg & $78.9 \pm 15.8$ & $78.1 \pm 16.2$ & $79.6 \pm 15.5$ & 0.31 \\
\hline \multicolumn{5}{|l|}{ Body composition } \\
\hline Height, $\mathrm{cm}$ & $173.9 \pm 9.7$ & $173.4 \pm 10.6$ & $174.3 \pm 9.0$ & 0.30 \\
\hline BMI, $\mathrm{kg} / \mathrm{m}^{2}$ & $26.0 \pm 4.5$ & $25.9 \pm 4.6$ & $26.1 \pm 4.5$ & 0.60 \\
\hline \multicolumn{5}{|l|}{ Waist circumference, $\mathrm{cm}$} \\
\hline Men & $99.1 \pm 12.1$ & $98.7 \pm 12.2$ & $99.5 \pm 12.1$ & 0.98 \\
\hline Women & $93.0 \pm 15.8$ & $92.6 \pm 15.3$ & $93.4 \pm 16.3$ & 0.68 \\
\hline \multicolumn{5}{|l|}{ Circulation } \\
\hline Heart rate, bpm & $67.6 \pm 12.0$ & $67.8 \pm 12.3$ & $67.4 \pm 11.8$ & 0.72 \\
\hline $\mathrm{SBP}, \mathrm{mm} \mathrm{Hg}$ & $135.3 \pm 17.0$ & $135.7 \pm 16.3$ & $135.0 \pm 17.7$ & 0.68 \\
\hline $\mathrm{DBP}, \mathrm{mm} \mathrm{Hg}$ & $83.0 \pm 11.0$ & $83.3 \pm 11.1$ & $82.8 \pm 11.0$ & 0.61 \\
\hline \multicolumn{5}{|l|}{ Renal function } \\
\hline eGFR, mL/min per $1.73 \mathrm{~m}^{2}$ & $53.1 \pm 20.2$ & $52.3 \pm 21.6$ & $53.7 \pm 18.8$ & 0.45 \\
\hline \multicolumn{5}{|l|}{ Laboratory parameters } \\
\hline Triglycerides, $\mathrm{mmol} / \mathrm{L}$ & $1.6(1.2-2.1)$ & $1.7(1.2-2.3)$ & $1.5(1.1-2.0)$ & 0.04 \\
\hline HDL cholesterol, $\mathrm{mmol} / \mathrm{L}$ & $1.4 \pm 0.5$ & $1.4 \pm 0.4$ & $1.5 \pm 0.5$ & 0.001 \\
\hline Fasting glucose, mmol/L & $5.1(4.7-5.5)$ & $5.1(4.7-5.5)$ & $5.0(4.7-5.5)$ & 0.51 \\
\hline Hepatitis C virus, n (\%) & $6(1.3)$ & $3(1.4)$ & $3(1.2)$ & 0.86 \\
\hline \multicolumn{5}{|l|}{ Cytomegalovirus, n (\%) } \\
\hline Primary infection & $99(21.2)$ & $48(22.1)$ & $51(20.3)$ & 0.63 \\
\hline Reactivation & $80(17.1)$ & $38(17.5)$ & $42(16.7)$ & 0.69 \\
\hline \multicolumn{5}{|l|}{ Primary renal disease } \\
\hline Polycystic kidney disease, n (\%) & $103(22.0)$ & $47(21.7)$ & $56(22.3)$ & 0.87 \\
\hline Nephrosclerosis, n (\%) & $139(29.7)$ & $67(30.9)$ & $72(28.7)$ & 0.61 \\
\hline \multicolumn{5}{|l|}{ Transplant characteristics } \\
\hline Transplant vintage, years & $5.6(2.1-12.3)$ & $5.2(2.2-12.3)$ & $5.8(1.8-12.3)$ & 0.80 \\
\hline Living donor, n (\%) & $168(35.9)$ & $70(32.3)$ & $98(39.0)$ & 0.20 \\
\hline Pre-emptive transplant, $\mathrm{n}(\%)$ & $84(17.9)$ & $32(14.7)$ & $52(20.7)$ & 0.09 \\
\hline Dialysis duration, months & $37.0(16.0-60.0)$ & $46.0(15.0-63.0)$ & $32.0(17.0-56.0)$ & 0.30 \\
\hline Age donor, years & $43.0 \pm 15.5$ & $42.6 \pm 15.0$ & $43.4 \pm 15.9$ & 0.61 \\
\hline Cold ischemia time, hours & $14.0(3.0-21.0)$ & $16.0(3.0-21.0)$ & $12.0(3.0-21.0)$ & 0.06 \\
\hline Warm ischemia time, minutes & $40(33-50)$ & $42(33-51)$ & $39(34-48)$ & 0.25 \\
\hline Acute rejection, n (\%) & $114(24.4)$ & $49(22.6)$ & $65(25.9)$ & 0.41 \\
\hline \multicolumn{5}{|l|}{ Medication } \\
\hline Cyclosporine, n (\%) & $178(38.0)$ & $82(37.8)$ & $96(38.2)$ & 0.92 \\
\hline Tacrolimus, n (\%) & $79(16.9)$ & $44(20.3)$ & 35 (13.9) & 0.07 \\
\hline mTOR inhibitor, $\mathrm{n}(\%)$ & $5(1.1)$ & $2(0.9)$ & $3(1.2)$ & 0.76 \\
\hline Prednisolone dose, mg & $10.0(7.5-10.0)$ & $10.0(7.5-10.0)$ & $10.0(7.5-10.0)$ & 0.70 \\
\hline Cumulative prednisolone dose, $\mathrm{g}$ & $18.3(7.4-38.1)$ & $18.3(7.8-36.6)$ & $18.2(7.4-40.4)$ & 0.86 \\
\hline Diuretics, n (\%) & $158(33.8)$ & $76(35.0)$ & $82(32.7)$ & 0.59 \\
\hline$\beta$ blocker, n (\%) & $284(60.7)$ & $126(58.1)$ & $158(62.9)$ & 0.28 \\
\hline ACE inhibitor, n (\%) & $158(33.8)$ & $73(33.6)$ & $85(33.9)$ & 0.96 \\
\hline Angiotensin II receptor blocker, n (\%) & $71(15.2)$ & $39(18.0)$ & 32 (12.7) & 0.12 \\
\hline Statins, $n(\%)$ & $232(49.6)$ & $100(46.1)$ & $132(52.6)$ & 0.15 \\
\hline
\end{tabular}

Data are represented as mean $\pm S D$, median (IQR) or $n(\%)$. Differences were tested by t-test or Mann-Whitney $\mathrm{U}$ test for continuous variables and with $\chi^{2}$ test for categorical variables.

BMI, body mass index; DBP, diastolic blood pressure; eGFR, estimated glomerular filtration rate; HDL, high-density lipoprotein; MDS, Mediterranean Diet Score; RTR, renal transplant recipients; SBP, systolic blood pressure. 
Table 2 Median intake of the components of the Mediterranean Diet Score

\begin{tabular}{|c|c|c|c|c|}
\hline & \multicolumn{2}{|l|}{$\begin{array}{l}\text { Group } 1(0-4) \\
\text { Median (IQR) }\end{array}$} & \multicolumn{2}{|l|}{$\begin{array}{l}\text { Group } 2(5-9) \\
\text { Median (IQR) }\end{array}$} \\
\hline & Men & Women & Men & Women \\
\hline Ratio monounsaturated: saturated fatty acids & $0.9(0.8-1.0)$ & $0.9(0.8-1.0)$ & $1.0(0.9-1.1)$ & $1.0(0.9-1.1)$ \\
\hline Legumes, nuts and soy products (g/day) & $29(16-39)$ & $28(18-40)$ & $52(38-72)$ & $44(32-71)$ \\
\hline Cereals (g/day) & $176(128-240)$ & $134(107-178)$ & $210(170-257)$ & $175(141-206)$ \\
\hline Fruit (g/day) & $77(34-137)$ & $105(57-211)$ & $135(81-234)$ & $211(97-249)$ \\
\hline Vegetables (g/day) & $57(32-77)$ & $64(48-87)$ & $100(74-140)$ & $124(92-153)$ \\
\hline Meat products (g/day) & $109(82-128)$ & $94(77-116)$ & $90(70-115)$ & 79 (58-99) \\
\hline Dairy products (g/day) & $357(234-511)$ & $399(253-492)$ & $330(211-481)$ & $369(217-507)$ \\
\hline Fish (\%) & 34 & 34 & 57 & 67 \\
\hline Alcohol (\%) & 67 & 84 & 48 & 80 \\
\hline
\end{tabular}

the RTR that developed NODAT required treatment with hypoglycemic agents or insulin and in the high MDS group, $5(100 \%)$ of the RTR that developed NODAT required treatment with hypoglycemic agents or insulin. Median intake for the nine food groups of the MDS for both men and women are shown in table 2. In the low MDS group men had a higher intake of cereals and alcohol, whereas women had a higher intake of fruit. In the high MDS group men had a higher intake of cereals, whereas women had a high intake of fruit and vegetables. Intake of other food groups is approximately equal between male and female RTR. The high MDS group had a higher intake of legumes, cereals, vegetables, fruit, fish and alcohol compared to the low MDS group.

The Kaplan-Meier survival curves for the associations of the MDS with NODAT ( $p=0.003, \log$ rank test) and all-cause mortality $(\mathrm{p}=0.09, \log$ rank test) are shown in figure 2. RTR with MDS scores $\geq 5$ points were significantly associated with a lower risk of NODAT (OR: 0.23; $95 \%$ CI 0.09 to $0.64 ; \mathrm{p}=0.004)$ and all-cause mortality (hazards ratio (HR): $0.51 ; 95 \%$ CI 0.29 to $0.89, \mathrm{p}=0.02$ ), adjusted for age and sex (tables 3 and 4 ). The results of multivariable analyses, in which we additionally adjusted for use of medication, pre-emptive transplantation and cold ischemia time, total energy intake, smoking behavior and physical activity, fasting triglycerides and HDL-cholesterol concentrations and time between transplantation and baseline, did not materially change the results of the analyses adjusted for age and sex (tables 3 and 4).

\section{CONCLUSIONS}

About $50 \%$ of the RTR had either a low or a high MDS. Patients with a high MDS had a four times lower risk of NODAT and a two times lower risk of all-cause mortality. These results suggest that a healthy diet is of paramount importance for patients who receive a new kidney.

Previous studies on diet and chronic diseases often focused on single nutrients. However, food-based dietary patterns take into account complex interactions between food items and are easier to interpret. Another advantage of foods and dietary patterns is that they can directly be transplanted into dietary recommendations to be used in clinical practice. ${ }^{28} 29$

A meta-analysis of population-based prospective cohort studies showed that greater adherence to the Mediterranean Style diet was associated with a $20 \%$ lower all-cause mortality ${ }^{30}$ and $20 \%$ lower cardiovascular risk. $^{31}$ A meta-analysis of the adherence to the Mediterranean Style diet showed a 25\% lower incidence of diabetes mellitus among prospective cohort studies. ${ }^{15}$
Figure 2 Kaplan-Meier survival curves. Probability of survival for $\operatorname{NODAT}(A)$ and all-cause mortality (B) for both group 1 and group 2. NODAT, new-onset diabetes after transplantation.
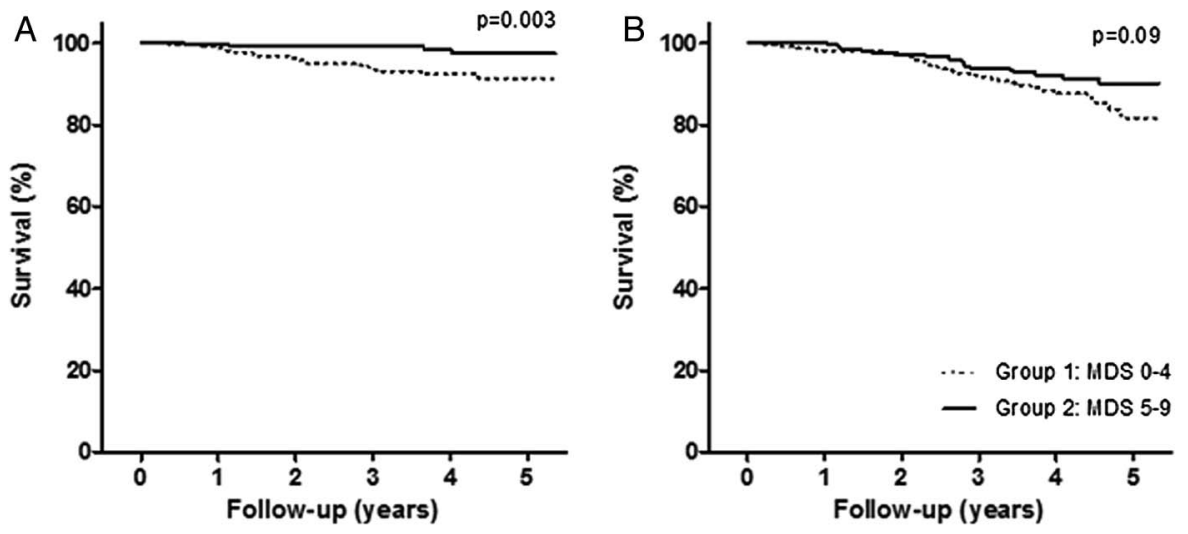
Table 3 Multiple logistic regression analysis

$$
\begin{array}{ll}
\text { Group } 1(0-4) & \text { Group } 2(5-9) \\
17(7.8 \%) & 5(2.0 \%)
\end{array}
$$

\begin{tabular}{llll}
$\begin{array}{l}\text { Number of } \\
\text { events }\end{array}$ & & OR $(95 \%$ Cl) & p Value \\
\hline Model 1 & 1.00 (ref) & $0.24(0.09$ to 0.66$)$ & 0.006 \\
Model 2 & 1.00 (ref) & $0.23(0.08$ to 0.63$)$ & 0.004 \\
Model 3 & 1.00 (ref) & $0.22(0.08$ to 0.62$)$ & 0.004 \\
Model 4 & 1.00 (ref) & $0.24(0.08$ to 0.69$)$ & 0.008 \\
Model 5 & 1.00 (ref) & $0.23(0.08$ to 0.63$)$ & 0.004 \\
Model 6 & 1.00 (ref) & $0.23(0.08$ to 0.65$)$ & 0.005 \\
Model 7 & 1.00 (ref) & $0.18(0.06$ to 0.54$)$ & 0.002 \\
Model 8 & 1.00 (ref) & $0.23(0.08$ to 0.63$)$ & 0.004 \\
\hline
\end{tabular}

The Mediterranean diet is associated with a lower risk to develop NODAT.

Model 1, crude.

Model 2, adjustment for age and sex.

Model 3, model 2+adjustment for cyclosporine, tacrolimus and prednisolone dose.

Model 4, model 2+adjustment for pre-emptive transplantation and cold ischemia time.

Model 5, model 2+adjustment for total energy intake.

Model 6 , model 2+adjustment for smoking and physical activity.

Model 7, model 2+adjustment for triglycerides and

HDL-cholesterol concentrations.

Model 8 , model 2+adjustment for time between transplantation and baseline.

HDL, high-density lipoprotein; NODAT, new-onset diabetes after transplantation.

To the best of our knowledge, this is the first study to investigate the association between a Mediterranean Style diet and risk of NODAT and all-cause mortality in RTR. In line with our results on NODAT another study showed an association between adherence to a Mediterranean Style diet and a lower incidence of metabolic syndrome after transplantation. ${ }^{32}$ Prospective cohort studies among patients with cardiovascular disease showed that a Mediterranean Style diet was associated with a lower risk of all-cause mortality. ${ }^{33-35}$ These results suggest that a Mediterranean Style diet is associated with a lower mortality risk in patients with renal transplant and also in patients with cardiovascular disease. This shows the great potential of a healthy diet in secondary prevention.

There are multiple mechanisms that might explain the protective effect of a Mediterranean Style diet on the development of NODAT and mortality in RTR. It is well known that insulin resistance and pancreatic $\beta$ cell dysfunction are two fundamental features that play an important role in the development of type 2 DM. ${ }^{36}$ High adherence to the Mediterranean Style diet is associated with a higher intake of antioxidants, dietary fiber, magnesium and unsaturated fatty acids. ${ }^{36}$ The Mediterranean diet may prevent cardiometabolic diseases through several pathways. First of all, prolonged oxidative stress contributes to the development of insulin resistance and pancreatic $\beta$-cell dysfunction. ${ }^{37} \mathrm{~A}$

\begin{tabular}{|c|c|c|c|}
\hline \multirow{2}{*}{$\begin{array}{l}\text { Number of } \\
\text { events }\end{array}$} & \multirow[t]{2}{*}{$\begin{array}{l}\text { Group } 1(0-4) \\
29(13.4 \%)\end{array}$} & \multicolumn{2}{|l|}{$\begin{array}{l}\text { Group } 2(5-9) \\
21(8.4 \%)\end{array}$} \\
\hline & & HR (95\% Cl) & p Value \\
\hline Model 1 & 1.00 (ref) & $0.62(0.35$ to 1.09$)$ & 0.09 \\
\hline Model 2 & 1.00 (ref) & 0.51 (0.29 to 0.89$)$ & 0.02 \\
\hline Model 3 & 1.00 (ref) & $0.52(0.29$ to 0.92$)$ & 0.03 \\
\hline Model 4 & 1.00 (ref) & 0.52 (0.27 to 0.99$)$ & 0.05 \\
\hline Model 5 & 1.00 (ref) & 0.51 (0.29 to 0.89$)$ & 0.02 \\
\hline Model 6 & 1.00 (ref) & $0.57(0.22$ to 1.03$)$ & 0.06 \\
\hline Model 7 & (ref) & to 1.02$)$ & 0.06 \\
\hline Model 8 & 1.00 (ref) & 0.50 (0.29 to 0.89$)$ & 0.02 \\
\hline \multicolumn{4}{|c|}{$\begin{array}{l}\text { The Mediterranean diet is associated with a lower risk of mortality } \\
\text { during follow-up. } \\
\text { Model 1, crude. } \\
\text { Model 2, adjustment for age and sex. } \\
\text { Model 3, model 2+adjustment for cyclosporine, tacrolimus and } \\
\text { prednisolone dose. } \\
\text { Model 4, model 2+adjustment for pre-emptive transplantation and } \\
\text { cold ischemia time. } \\
\text { Model 5, model 2+adjustment for total energy intake. } \\
\text { Model 6, model 2+adjustment for smoking and physical activity. } \\
\text { Model 7, model 2+adjustment for triglycerides and } \\
\text { HDL-cholesterol concentrations. } \\
\text { Model 8, model 2+adjustment for time between transplantation } \\
\text { and baseline. } \\
\text { HDL, high-density lipoprotein. }\end{array}$} \\
\hline
\end{tabular}
Mediterranean Style diet might have a protective effect on oxidative stress and antioxidant defense, since this dietary pattern is characterized by high intake of fruit and vegetables. ${ }^{38}$ Second, the high intake of dietary fiber might reduce plasma insulin levels and have an advantageous effect on glucose metabolism. ${ }^{36}$ Third, magnesium might play an important role in preventing type $2 \mathrm{DM} .{ }^{36}$ Previous studies showed that high intake of magnesium is associated with a lower risk of developing type 2 diabetes. ${ }^{39} 40$

Also fatty acids could play a role in the prevention of cardiometabolic diseases. A high ratio of monounsaturated: saturated fatty acids improves insulin sensitivity. ${ }^{41}$ A high intake of monounsaturated fatty acids benefits glycemic control, since it stimulates the secretion of glucagon-like peptide-1 (GLP-1), an antidiabetic hormone. ${ }^{42}$ GLP-1 activates the GLP-1 receptor in the pancreatic islets, which leads to an increase in secretion of insulin and inhibition of glucagon. ${ }^{43}$ Furthermore, GLP-1 plays a role in satiety. ${ }^{44}$

Finally, pathological processes as inflammation and endothelial dysfunction play a role in the etiology of cardiovascular events. ${ }^{45} 46$ A previous study showed that higher adherence to a Mediterranean Style diet is associated with a lower concentration of biomarkers for inflammation and endothelial dysfunction; $\mathrm{C}$ reactive protein, interleukin-6, E-selectin and soluble intercellular cell adhesion molecule-1. ${ }^{47}$ Furthermore, the literature shows that olive oil, vegetables, cereals and nuts have antithrombotic and/or anticoagulant effects. ${ }^{46}$ Adherence to a Mediterranean Style diet is associated with lower levels of prothrombotic biomarkers, for example, fibrogen, ${ }^{48}$ which contributes to a lower cardiovascular risk as well. 
Our study has several limitations. Although this is a prospective cohort study, causality of the associations cannot be assumed, since this study is of observational nature. Also the number of NODAT cases and the number of deaths is small. Furthermore, the FFQ was originally developed to examine protein intake in RTR. It was only validated by comparing the protein intake of the FFQ with the protein intake calculated by the Maroni Equation, using urinary urea excretion values. ${ }^{19}$ The Mediterranean Style diet of our RTR is not optimal and may further lower the risk of NODAT and all-cause mortality through a better adherence to the traditional Mediterranean diet. It is the first time the association between the Mediterranean Style diet and NODAT and all-cause mortality is investigated in RTR. Furthermore, strengths include a complete follow-up of the clinically relevant end points: NODAT and all-cause mortality.

In conclusion, our prospective cohort study suggests that higher adherence to a Mediterranean Style diet may prevent the development of NODAT and all-cause mortality in RTR. More attention is needed for the nutritional habits of RTR.

\section{Author affiliations}

${ }^{1}$ Department of Internal Medicine, Division of Nephrology, University of Groningen, University Medical Center Groningen, Groningen, The Netherlands ${ }^{2}$ Department of Epidemiology, University of Groningen, University Medical Center Groningen, Groningen, The Netherlands

${ }^{3}$ Department of Human Nutrition, University of Wageningen, Wageningen, The Netherlands

Acknowledgements The cohort on which the study was based is registered at clinicaltrials.gov as "TransplantLines Food and Nutrition Biobank and Cohort Study (TxL-FN)" with number NCT02811835.

Contributors MCJO analyzed the data and wrote the first draft of the paper. EC, GJN, CAK, DK and SJLB contributed to the interpretation of the results and important intellectual content. MCJO, EB, CAK and MHdB collaborated in the data collection. All authors had access to the data, contributed to the critical revision of the manuscript and approved the final version of the manuscript.

Funding This work was supported by a grant from the Dutch Top Institute Food and Nutrition (A-1003).

Competing interests None declared.

Ethics approval METc 2008/186.

Provenance and peer review Not commissioned; externally peer reviewed.

Data sharing statement No additional data are available.

Open Access This is an Open Access article distributed in accordance with the terms of the Creative Commons Attribution (CC BY 4.0) license, which permits others to distribute, remix, adapt and build upon this work, for commercial use, provided the original work is properly cited. See: http:// creativecommons.org/licenses/by/4.0/

\section{REFERENCES}

1. Lysaght MJ. Maintenance dialysis population dynamics: current trends and long-term implications. J Am Soc Nephrol 2002;13(Suppl 1):S37-40.

2. Ponton P, Rupolo GP, Marchini F, et al. Quality-of-life change after kidney transplantation. Transplant Proc 2001;33:1887-9.

3. Wolfe RA, Ashby VB, Milford EL, et al. Comparison of mortality in all patients on dialysis, patients on dialysis awaiting transplantation, and recipients of a first cadaveric transplant. $N$ Engl J Med 1999;341:1725-30.

4. Hjelmesaeth $\mathrm{J}$, Midtvedt $\mathrm{K}$, Jenssen $\mathrm{T}$, et al. Insulin resistance after renal transplantation: impact of immunosuppressive and antihypertensive therapy. Diabetes Care 2001;24:2121-6.

5. Chadban S. New-onset diabetes after transplantation-should it be a factor in choosing an immunosuppressant regimen for kidney transplant recipients. Nephrol Dial Transplant 2008;23:1816-18.

6. Montori VM, Basu A, Erwin PJ, et al. Posttransplantation diabetes: a systematic review of the literature. Diabetes Care 2002;25:583-92

7. Jardine AG, Gaston RS, Fellstrom BC, et al. Prevention of cardiovascular disease in adult recipients of kidney transplants. Lancet 2011;378:1419-27.

8. Zelle DM, Corpeleijn E, Deinum J, et al. Pancreatic beta-cell dysfunction and risk of new-onset diabetes after kidney transplantation. Diabetes Care 2013;36:1926-32.

9. Rodrigo E, Fernandez-Fresnedo G, Valero R, et al. New-onset diabetes after kidney transplantation: risk factors. J Am Soc Nephrol 2006;17(Suppl 3):S291-5.

10. Kaposztas Z, Gyurus E, Kahan BD. New-onset diabetes after renal transplantation: diagnosis, incidence, risk factors, impact on outcomes, and novel implications. Transplant Proc 2011;43:1375-94.

11. Wauters RP, Cosio FG, Suarez Fernandez ML, et al. Cardiovascular consequences of new-onset hyperglycemia after kidney transplantation. Transplantation 2012;94:377-82.

12. Zelle DM, Kok T, Dontje ML, et al. The role of diet and physical activity in post-transplant weight gain after renal transplantation. Clin Transplant 2013;27:E484-90.

13. Halton TL, Hu FB. The effects of high protein diets on thermogenesis, satiety and weight loss: a critical review. J Am Coll Nutr 2004:23:373-85.

14. van den Ham EC, Kooman JP, Christiaans $\mathrm{MH}$, et al. Weight changes after renal transplantation: a comparison between patients on 5-mg maintenance steroid therapy and those on steroid-free immunosuppressive therapy. Transpl Int 2003;16:300-6.

15. Esposito K, Maiorino MI, Bellastella G, et al. A journey into a Mediterranean diet and type 2 diabetes: a systematic review with meta-analyses. BMJ Open 2015;5:e008222.

16. Schwingshackl L, Missbach B, Konig J, et al. Adherence to a Mediterranean diet and risk of diabetes: a systematic review and meta-analysis. Public Health Nutr 2015;18:1292-9.

17. Estruch R, Ros E, Salas-Salvado J, et al. Primary prevention of cardiovascular disease with a Mediterranean diet. $N$ Engl J Med 2013;368:1279-90.

18. van den Berg E, Geleijnse JM, Brink EJ, et al. Sodium intake and blood pressure in renal transplant recipients. Nephrol Dial Transplant 2012;27:3352-9.

19. van den Berg E, Engberink MF, Brink EJ, et al. Dietary protein, blood pressure and renal function in renal transplant recipients. Br J Nutr 2013;109:1463-70.

20. Wendel-Vos GC, Schuit AJ, Saris WH, et al. Reproducibility and relative validity of the short questionnaire to assess health-enhancing physical activity. J Clin Epidemiol 2003;56: 1163-9.

21. Levey AS, Stevens LA, Schmid CH, et al. A new equation to estimate glomerular filtration rate. Ann Intern Med 2009;150:604-12.

22. Feunekes GI, Van Staveren WA, De Vries JH, et al. Relative and biomarker-based validity of a food-frequency questionnaire estimating intake of fats and cholesterol. Am J Clin Nutr 1993;58:489-96.

23. van den Berg E, Engberink MF, Brink EJ, et al. Dietary acid load and metabolic acidosis in renal transplant recipients. Clin J Am Soc Nephrol 2012;7:1811-18.

24. Trichopoulou A, Costacou T, Bamia C, et al. Adherence to a Mediterranean diet and survival in a Greek population. $N$ Engl $\mathrm{J}$ Med 2003;348:2599-608.

25. Zelle DM, Agarwal PK, Ramirez JL, et al. Alcohol consumption, new onset of diabetes after transplantation, and all-cause mortality in renal transplant recipients. Transplantation 2011;92:203-9.

26. First MR, Dhadda S, Croy R, et al. New-onset diabetes after transplantation (NODAT): an evaluation of definitions in clinical trials. Transplantation 2013;96:58-64.

27. Vittinghoff $\mathrm{E}, \mathrm{McC}$ (lloch $\mathrm{CE}$. Relaxing the rule of ten events per variable in logistic and Cox regression. Am J Epidemiol 2007;165:710-18.

28. Hu FB, Rimm EB, Stampfer MJ, et al. Prospective study of major dietary patterns and risk of coronary heart disease in men. Am $J$ Clin Nutr 2000;72:912-21. 
29. Hu FB. Dietary pattern analysis: a new direction in nutritional epidemiology. Curr Opin Lipidol 2002;13:3-9.

30. Sofi F, Macchi C, Abbate R, et al. Mediterranean diet and health status: an updated meta-analysis and a proposal for a literature-based adherence score. Public Health Nutr 2014;17:2769-82.

31. Martinez-Gonzalez MA, Bes-Rastrollo M. Dietary patterns, Mediterranean diet, and cardiovascular disease. Curr Opin Lipidol 2014:25:20-6.

32. Nafar M, Noori N, Jalali-Farahani S, et al. Mediterranean diets are associated with a lower incidence of metabolic syndrome one year following renal transplantation. Kidney Int 2009;76:1199-206.

33. lestra J, Knoops K, Kromhout D, et al. Lifestyle, Mediterranean diet and survival in European post-myocardial infarction patients. Eur J Cardiovasc Prev Rehabil 2006;13:894-900.

34. Barzi F, Woodward M, Marfisi RM, et al. Mediterranean diet and all-causes mortality after myocardial infarction: results from the GISSI-Prevenzione trial. Eur J Clin Nutr 2003;57:604-11.

35. Lopez-Garcia E, Rodriguez-Artalejo F, Li TY, et al. The

Mediterranean-style dietary pattern and mortality among men and women with cardiovascular disease. Am J Clin Nutr 2014:99:172-80.

36. Schroder H. Protective mechanisms of the Mediterranean diet in obesity and type 2 diabetes. J Nutr Biochem 2007;18:149-60.

37. Evans JL, Goldfine ID, Maddux BA, et al. Are oxidative stress-activated signaling pathways mediators of insulin resistance and beta-cell dysfunction? Diabetes 2003;52:1-8.

38. Schroder $\mathrm{H}$, Marrugat $\mathrm{J}$, Vila J, et al. Adherence to the traditional Mediterranean diet is inversely associated with body mass index and obesity in a Spanish population. J Nutr 2004;134:3355-61.
39. Kao WH, Folsom AR, Nieto FJ, et al. Serum and dietary magnesium and the risk for type 2 diabetes mellitus: the Atherosclerosis Risk in Communities Study. Arch Intern Med 1999;159:2151-9.

40. Lopez-Ridaura R, Willett WC, Rimm EB, et al. Magnesium intake and risk of type 2 diabetes in men and women. Diabetes Care 2004;27:134-40.

41. Martinez-Gonzalez MA, de la Fuente-Arrillaga C, Nunez-Cordoba $\mathrm{JM}$, et al. Adherence to Mediterranean diet and risk of developing diabetes: prospective cohort study. BMJ 2008;336:1348-51.

42. Rocca AS, LaGreca J, Kalitsky J, et al. Monounsaturated fatty acid diets improve glycemic tolerance through increased secretion of glucagon-like peptide-1. Endocrinology 2001:142:1148-55

43. Komatsu R, Matsuyama T, Namba M, et al. Glucagonostatic and insulinotropic action of glucagonlike peptide I-(7-36)-amide. Diabetes 1989;38:902-5.

44. Turton MD, O'Shea D, Gunn I, et al. A role for glucagon-like peptide-1 in the central regulation of feeding. Nature 1996;379:69-72.

45. Esposito K, Marfella R, Ciotola M, et al. Effect of a Mediterranean-style diet on endothelial dysfunction and markers of vascular inflammation in the metabolic syndrome: a randomized trial. JAMA 2004;292:1440-6.

46. Delgado-Lista J, Perez-Martinez P, Garcia-Rios A, et al. Mediterranean diet and cardiovascular risk: beyond traditional risk factors. Crit Rev Food Sci Nutr 2016;56:788-801.

47. Fung TT, McCullough ML, Newby PK, et al. Diet-quality scores and plasma concentrations of markers of inflammation and endothelial dysfunction. Am J Clin Nutr 2005;82:163-73.

48. Carter SJ, Roberts MB, Salter J, et al. Relationship between Mediterranean Diet Score and atherothrombotic risk: findings from the Third National Health and Nutrition Examination Survey (NHANES III), 1988-1994. Atherosclerosis 2010;210:630-6. 